\title{
Synthesis and characterization of a polyurethane carrier used for a prolonged transmembrane transfer of a chili pepper extract
}

This article was published in the following Dove Press journal: International Journal of Nanomedicine

\author{
Livia-Cristina Borcan ${ }^{1, *}$ \\ Zoltan Dudas ${ }^{2,3, *}$ \\ Adel Len ${ }^{2,4}$ \\ Janos Fuzi ${ }^{2,4}$ \\ Florin Borcan ${ }^{5}$ \\ Mirela Cleopatra Tomescu' \\ 'The 5th Department (Internal \\ Medicine I), Faculty of Medicine, \\ "Victor Babes" University of \\ Medicine and Pharmacy, Timisoara, \\ Romania; ${ }^{2}$ Neutron Spectroscopy \\ Department, Institute for Solid \\ State Physics and Optics, Wigner \\ Research Centre for Physics, \\ Hungarian Academy of Sciences, \\ Budapest, Hungary; ${ }^{3}$ norganic \\ Department, Institute of Chemistry, \\ Romanian Academy, Timisoara, \\ Romania; ${ }^{4} \mathrm{Faculty}$ of Engineering and \\ Information Technology, University \\ of Pécs, Pécs, Hungary; ${ }^{5}$ The Ist \\ Department (Analytical Chemistry), \\ Faculty of Pharmacy, "Victor Babes" \\ University of Medicine and Pharmacy, \\ Timisoara, Romania \\ *These authors contributed equally \\ to this work
}

Purpose: Red chili peppers have been highly valued in gastronomy and traditional medicine since ancient times; it seems that it is not just an ingredient for food but also a good remedy for various medical conditions such as increased blood pressure and high levels of serum triglycerides and cholesterol, myocardial infarction, arthritis, and migraines. The objective of this study is the characterization of a new carrier used for encapsulated extract.

Methods: Chili pepper extract was obtained and was physically entrapped inside polyurethane microparticles in order to diminish the irritative potential of this extract. The particles were evaluated by Zetasizer measurements, small-angle neutron scattering and thermal analysis, scanning electron microscopy (SEM), and Fourier transform infrared spectroscopy; the encapsulation efficacy and the drug release profile were assessed by UV-Vis spectroscopy. Bioevaluations on mice skin were performed to predict the irritative potential of the samples.

Results: Two different types of samples were compared: hollow polyurethane microparticles vs polyurethane particles containing the natural extract. The sizes of the particles were very similar, but the sample containing the extract presents three particle populations (the polydispersity index increases from 0.3 to 0.6 from one sample to another). The zeta-potential measurements and SEM images indicate a medium tendency to form clusters, while the UV-Vis study revealed an almost $70 \%$ encapsulation efficacy.

Conclusion: The results suggest that encapsulation of a chili pepper extract inside polyurethane microparticles leads to a non-irritative product with a prolonged release: $\sim 30 \%$ of encapsulated extract is released within the first 8 days and a maximum $45 \%$ is reached in 2 weeks.

Keywords: corneometry, drug delivery system, erythema, FTIR, SANS, UV-Vis, zeta-potential

\section{Introduction}

Traditional remedies based on medicinal plants appeared a few millennia ago and they have experienced an exponential growth as herbal medicine in the last decades. Chili pepper was found in America and it is spread all over the world after Columbus discovered it; nowadays, more than $90 \%$ of chili peppers are produced in Asia, and almost one-fourth of the global population consumes it including for its pharmacologic properties. $^{1,2}$

The dried fruits of red chili pepper contain 18\% proteins, $\sim 3 \%$ fats, $26 \%$ cellulose, $6 \%$ reductive sugars, $9 \mathrm{mg} / \mathrm{kg} \mathrm{Cu}, 14 \mathrm{mg} / \mathrm{kg} \mathrm{Zn,} 80 \mathrm{mg} / \mathrm{kg} \mathrm{Mn}$, and around $160 \mathrm{mg} / \mathrm{kg}$ Fe. ${ }^{3,4}$ Beta-Ionone was found as the main volatile compound that is responsible for the chili peppers' odor. ${ }^{5}$ Freire et $\mathrm{al}^{6}$ found the following organic compounds in different chili pepper extracts: flavones, flavonols, xanthones (fraction in hexane or ethyl acetate of the ethanol extract), and free steroids (fraction in ethyl acetate or methanol
The Ist Department (Analytica Chemistry), Faculty of Pharmacy, "Victor Babes" University of Medicine and Pharmacy, 2nd Eftimie Murgu Sq., Timisoara 30004I, Romania

Tel +40 722 37। 025

Fax +40 356780037

Email fborcan@umft.ro 
of the ethanol extract), while saponins were found just in the fraction in methanol of the ethanol extract.

Ingested capsaicinoids (CAPs) reduce adverse effects due to a high-fat and a high-carbohydrate diet. It is known that the metabolic syndrome is a global health problem with increased morbidity and it comprises many risk factors like insulin resistance, obesity, hyperglycemia, hypertension, and dyslipidemia. ${ }^{7-9}$ Chapa-Oliver et $\mathrm{al}^{10}$ described that CAPs from chili peppers alter the expression of several genes involved in cancer cell survival, growth arrest, angiogenesis, and metastasis.

The CAPs from chili pepper extract present some physiologic properties involved in lipolysis based on the association with PPAR-alpha and TRPV-1 expression/activation, thermogenesis by activating the sarcoplasmic reticulum $\mathrm{Ca}^{++}$ATPase and decreasing the ability to feel pain by linking them to the vanilloid receptor subtype 1. A few studies revealed that these compounds improve the endothelial function by inhibiting the gene expression of cyclooxygenase-2, increase the fecal excretion of sterols in animal models and the resistance of serum lipoproteins to oxidation, inhibit low-density lipoprotein-cholesterol oxidation, decrease the cholesterol absorption and plasmatic campesterol/cholesterol ratio, and maintain aortic integrity. ${ }^{11,12}$

The daily consumption of chili peppers is between 1 and 12 $\mathrm{g} /$ person. Deshpande et a ${ }^{13}$ published a pilot study on the tolerability of CAPs from capsicum extract; they used an ascending dose protocol on 12 healthy females between 25 and 55 years old with a body mass index between 25 and $35 \mathrm{~kg} / \mathrm{m}^{2}$ and did not find any significant effect on skin and hair, bowel movements, breathing, urination, clinical chemistries, metabolic measures, and vital signs compared to the baseline measurements. A study on the topical applications of CAP solutions in 84 patients with postsurgical peripheral neuropathic pain revealed that the treatment was generally well tolerated, with $\sim 7 \%$ of patients needing a medication to alleviate the side effects (erythema and burning sensations) in comparison to the $15 \%-44 \%$ often reported in other clinical trials. ${ }^{14}$

Despite all beneficial properties of the chili peppers, the excessive consumption of spicy food can cause digestive problems and the topical applications are limited to the patients with very sensitive skin. The drug delivery systems with a controlled and targeted release represent an alternative administration of a chili pepper extract. Lenzi et a ${ }^{15}$ studied the diffusion process and the release of CAPs from poly( $\varepsilon$-caprolactone) microparticles; they obtained spherical particles that can deliver the CAPs rapidly to initiate the therapeutic effect, and the experimental release and diffusion profile were very similar to others estimated by Fick's law. Hydroxypropyl-beta-cyclodextrin, carboxymethyl-chitosansodium hydrogels, polyethylene glycol-polylactic-coglycolic acid thermosensitive hydrogel, flexible membrane vesicles, niosomal carriers, liposomes, and nanofibers were also developed as CAP carriers. ${ }^{16}$

The aim of this research was to obtain a polyurethane (PU) carrier used for the transmembrane passing of chili pepper extract and the evaluation of its physical and chemical properties and its release rate.

\section{Materials and methods Raw materials}

The reagents used for the carrier synthesis are ethylene glycol (EG) from Lach-Ner s.r.o. (Neratovice, Czech Rep.), 1,4-butanediol (BD) from Carl Roth GmbH (Karlsruhe, Germany), hexamethylene diisocyanate (HMDI), polyethylene glycol M=200 (PEG), and the solvent (acetone) from Merck (Darmstadt, Germany). The emulsifier, Isolan ${ }^{\circledR}$ GI34, was kindly donated by our colleagues from School of Pharmacy, Szeged University, Hungary. The substances were maintained in proper conditions before the chemical reactions (conditions mentioned by the suppliers); however, PEG was purified by vacuum filtration at low pressure using a Buchner flask ( $25 \mathrm{mmHg}$ ), and EG was purified by distillation in order to remove any impurity.

The inorganic salts $\left(\mathrm{NaCl}, \mathrm{NaHCO}_{3}, \mathrm{Na}_{2} \mathrm{HPO}_{4}, \mathrm{KCl}\right.$, $\mathrm{KH}_{2} \mathrm{PO}_{4}, \mathrm{~K}_{2} \mathrm{HPO}_{4}, \mathrm{MgCl}_{2}$ ) and $\mathrm{HCl}$ solution $1 \mathrm{M}$, used to obtain a degradation medium, were purchased from Chimopar (Bucharest, Romania); the salts (analytical grade, $<1.0 \%$ insoluble impurities) were previously heated at $110^{\circ} \mathrm{C}$ for 1 hour in order to remove the crystallization water.

\section{Extraction procedure}

Many extraction methods of CAPs from chili peppers were developed during the last decade; $\mathrm{Lu}$ et $\mathrm{al}{ }^{17}$ appreciated that sample quantity, solvent selection and quantity, extraction time and temperature, and the repeatability and reproducibility of the procedure are the main parameters that influence the extraction efficacy.

The chili peppers were harvested from Timis County (western region of Romania) from a vegetable garden far away from any important highway or industrial agent. They were picked 75-90 days after planting, when measured $\sim 3.5-4$ inches and were rapidly dried at $90^{\circ} \mathrm{C}$ for 48 hours according to a protocol described by Munteanu et al. ${ }^{18}$ Dried chili peppers' powder weighing $0.05 \mathrm{~g}$ were 
solubilized in $10 \mathrm{~mL}$ solvent (70\% ethanol) and was heated in a microwave-assisted extraction (500 W for 5 minutes) according to a procedure described in the literature. ${ }^{19,20}$ The extract was cooled and centrifuged at 4,000 rpm for 10 minutes.

\section{Synthesis of PU particles}

The synthesis of PU particles is based on a spontaneous emulsification combined with an interphase polyaddition reaction; it follows a procedure already presented by our research team in a series of scientific papers. ${ }^{21-23}$ It is a multiple-step protocol that begins with the preparation of an organic and an aqueous phase in separate lab flasks; the organic phase is prepared by the mixture of very small amounts of EG with the diisocyanate $(0.15 \mathrm{~mL} / 1.55 \mathrm{~mL})$ dissolved in $20.0 \mathrm{~mL}$ acetone under magnetic stirring (400 rpm) and light heating $\left(40^{\circ} \mathrm{C}\right)$. The addition in small amounts of diols in the organic phase is done to modify the viscosity and make it much closer to the viscosity of the aqueous phase; this is known as the semi-prepolymer method in the PU industry. On the other hand, in another flask, the aqueous phase was prepared by the mixture of surfactant with EG and PEG dissolved in distilled water under the same stirring speed and heating level. The next step is the rapid injection of one phase to the other at increased stirring speed (700 rpm) without any heating; the stirring was maintained for 4 hours to ensure the completion of all chemical reactions (no catalyst such as tertiary amines or metallic compounds was used). The third step of the protocol was the purification of the samples; they were washed with an acetone-water mixture $(1: 1, \mathrm{v} / \mathrm{v})$ and centrifuged at 4,500 rpm three times with a Hettich centrifuge EBA 20. The last step before any characterization was the drying process of the samples: water and acetone were removed by keeping the products as thin layers in plastic Petri dishes at $35^{\circ} \mathrm{C}$ in an oven for a few days; the samples were considered to be completely dry when the weight of the Petri dishes remained constant for 12 hours.

The previously presented protocol was repeated twice to obtain PU particles with and without chili pepper extract (Table 1).

\section{Stability evaluation}

The stability of PU particles with and without chili pepper extract was performed by keeping the two samples at $8^{\circ} \mathrm{C} \pm 0.3^{\circ} \mathrm{C}$ (in refrigerator), $25 \pm 0.5$ and $40^{\circ} \mathrm{C} \pm 0.5^{\circ} \mathrm{C}$, with $65 \% \pm 3 \%$ relative humidity (in a Pol-Eko drying oven). Physical parameters such as color, electrical conductivity, and $\mathrm{pH}$ were noted every third day for 1 month.

The color stability of the samples was monitored using the changes in the maximum absorbance (Amax) at 350 and $540 \mathrm{~nm}$ in order to find any hyperchromic effect and batochromic shift resulting from copigmentation reactions; an UVi Line 9400 Spectrophotometer (SI Analytics, Mainz, Germany), quartz cuvettes, and a background line were used. The electrical conductivity of samples was assessed by a Jenway Bench 4010 Conductivity meter (Cole-Parmer, Staffordshire, UK) at $25^{\circ} \mathrm{C}$ in diluted solutions (1:200, w/v). $\mathrm{pH}$ values were measured at $25^{\circ} \mathrm{C}$ using the same solutions and a Hanna Bench 2221 pH-meter (Hanna Instruments, Woonsocket, RI, USA); the instrument was previously calibrated using buffer solutions of HI 7004 (pH 4.01), HI 7007 (pH 7.01), and HI 7010 ( $\mathrm{pH}$ 10.01). All measurements were performed in triplicate and data were reported as the mean values.

\section{Zetasizer characterization}

The sizes of the particles and their surface charge were monitored with a Cordouan Zetasizer instrument (Cordouan Technology, France). The instrument is composed of a size analyzer, known as Vasco Particle Size Analyzer, and a zetapotential analyzer, called Wallis. The following parameters were chosen for these instruments: plastic cuvettes with working temperature $\left(20^{\circ} \mathrm{C}\right)$, laser power $(90 \% \pm 5 \%)$, number of channels ( 400$)$, and time interval (40 \pm 5 microseconds). Continuous acquisition mode with minimum five measures/ sequence (statistical distribution) at medium resolution with Pade-Laplace as analysis mode and Smoluchowski as Henry function was preferred to analyze the experimental data.

\section{Scanning electron microscopy (SEM)}

Topologic structural characteristics of the PU samples were determined in two different magnifications $(300 \times$ and $600 \times)$.

Table I The recipe of the synthesis

\begin{tabular}{|l|l|l|l|l|l|l|l|l|}
\hline \multirow{2}{*}{$\begin{array}{l}\text { Sample } \\
\text { code }\end{array}$} & \multicolumn{4}{|l|}{ Aqueous phase, $\mathbf{m L}$} & \multicolumn{2}{l|}{ Organic phase, $\mathbf{m L}$} & $\begin{array}{l}\text { Chili } \\
\text { pepper } \\
\text { extract, } \mathbf{m L}\end{array}$ \\
\cline { 2 - 9 } & EG & BD & PEG & $\begin{array}{l}\text { Isolan } \\
\text { GI 34 }\end{array}$ & $\begin{array}{l}\text { Distilled } \\
\text { water }\end{array}$ & EG/HMDI & Acetone & - \\
\hline PU_0 & 0.35 & 0.65 & 1.50 & 1.35 & 40.00 & $0.15 / 1.55$ & 20.00 & - \\
\hline PU_I & 0.35 & 0.65 & 1.50 & 1.35 & 40.00 & $0.15 / 1.55$ & 20.00 & 0.80 \\
\hline
\end{tabular}

Abbreviations: BD, I,4-butanediol; EG, ethylene glycol; HMDI, hexamethylene diisocyanate; PEG, polyethylene glycol. 
The high-voltage value was set at $20 \mathrm{kV}$. The samples were tested in their natural form under vacuum with TESCAN 3 VEGA scanning electron microscope secondary electron detector.

\section{Small-angle neutron scattering (SANS) analysis}

SANS method was used to determine the textural properties of PU microparticles. SANS provided information about the nanoscale pore characteristics, especially about the PU matrix-pore interface, in the whole volume of the sample. ${ }^{24}$

The Yellow Submarine (YS) and FSANS instruments operate at the Budapest Research Reactor (Hungary). YS is a pin-hole-type SANS instrument, while FSANS is a timeof-flight SANS instrument, both complementing each other in order to provide a wider scattering vector $(\mathrm{Q})$ range. The covered Q range was $0.003-0.020 \AA^{-1}$ for FSANS and 0.009-0.400 $\AA^{-1}$ for YS.

For YS a mean neutron wavelength of 4.38 and $10.23 \AA$ was chosen by a disc type velocity selector. The sample detector distance was 1.15 and $5.25 \mathrm{~m}$, respectively. A $8 \mathrm{~mm}$ diameter beam was used with $2 \mathrm{~mm}$ path length samples, contained in quartz cells, and with measurement times of 30-60 minutes.

For the FSANS measurement, wavelengths between 3 and $10 \AA$ were used with the aid of a neutron chopper system, the beam diameter was chosen as $5 \mathrm{~mm}$, and the measurement times were 10 hours.

The scattering data for both cases were corrected for the detector sensitivity, empty cell scattering, and background noise. The neutron intensity was recorded in function of the scattering vector Q, given by Equation 1 .

$$
\mathrm{Q}=\frac{4 \pi}{\lambda} \sin \frac{\theta}{2}
$$

where $\lambda$ is the wavelength of the monochromatic neutron beam and $\theta$ is the scattering angle.

The scattering from porous systems that are characterized by wide size distribution and high internal surface area can be described by fractal-like behavior that is related to the Porod approximation, described mathematically by Equation 2 .

$$
\mathrm{F}(\mathrm{Q})=\mathrm{K}^{2} V_{p}^{2} \exp \left(\mathrm{Q}^{-p}\right)
$$

where $F(Q)$ is the so-called form factor that is proportional to the recorded neutron intensity, $p$ is the Porod exponent, $\mathrm{K}$ is the neutron scattering contrast, and $V p$ is the volume of the scattering particles.
The values of the Porod exponent indicate smooth surfaces, when $P=4$; rough surfaces, when $P=3$; polymer chains of two-dimensional structures, when $P=2$; and stiff rods or thin cylinders, when $P=1$. The non-integer values of Porod exponent, smaller than 3 , indicate "mass fractals" and the values between 3 and 4 stand for "surface fractals". A surface fractal is characteristic to rough surfaces. ${ }^{25}$

\section{Fourier transform infrared (FTIR) spectra}

FTIR spectroscopy was employed to check the possible modifications caused by the incorporation of the CAPs in the PU microparticles. The spectra were recorded over a range of 4,000-400 $\mathrm{cm}^{-1}$ using a Cary 630 FTIR spectrophotometer.

\section{UV-Vis spectra}

The evaluation of the release rate of CAPs from the PU microparticles was performed using a procedure previously described in the literature by Albulescu et al. ${ }^{26}$ It is known that luteolin-rutinoside, luteolin-glucoside, myricetin, and kaempferol derivatives from chili pepper extracts are detected at $350 \mathrm{~nm} .{ }^{27}$ An UVi Line 9400 Spectrophotometer (SI Analytics, Germany) and Beer-Lambert law were used to determine the free CAPs content at every third day for 2 weeks while PU microparticles with chili pepper extract were maintained in a degradation medium; a calibration curve $\left(\mathrm{R}^{2}=0.983\right)$ was first drawn (Figure 1).

\section{Thermal decomposition}

The thermal behavior of PU samples was assayed by differential scanning calorimetry (DSC) carried out with a Mettler-Toledo DSC1 instrument (Mettler-Toledo, Greifensee, Switzerland). The samples were inserted in aluminum crucibles with pierced caps and were heated between $30^{\circ} \mathrm{C}$ and $300^{\circ} \mathrm{C}$ in an inert atmosphere $(100 \mathrm{~mL} / \mathrm{min} \mathrm{Ar})$ with a $5 \% \mathrm{~min}$ heating rate.

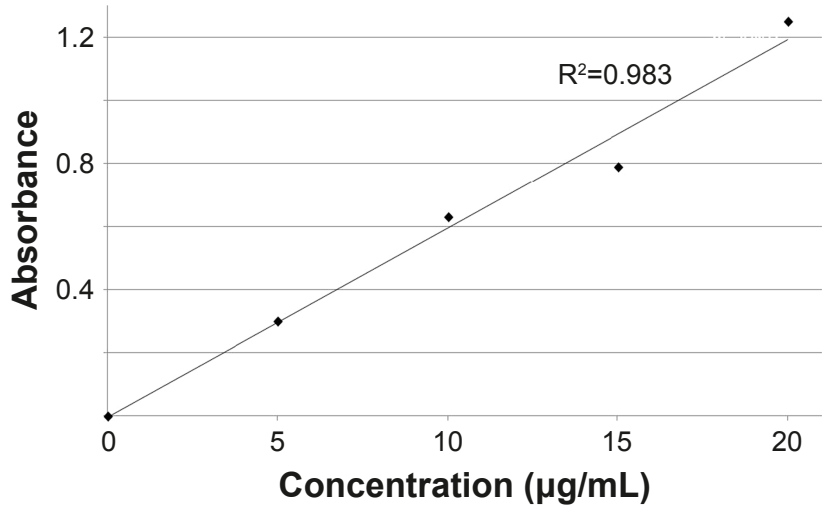

Figure I The calibration curve of CAPs. Abbreviation: CAPs, capsaicinoids. 
A reference material (empty aluminum crucible with pierced cap) simultaneously undergoes the same routine.

\section{Skin-sensitivity tests}

Nine hairless Balb/c female mice (12 weeks old, $\sim 30 \mathrm{~g}$ weight) were achieved from Charles River (Sulzfeld, Germany) and they were divided into three groups, labeled: 0 for mice treated with pure chili pepper extract and considered as reference group, PU_0 for mice treated with 3\% (w/v) aqueous suspension of empty PU microparticles, and PU_1 for mice treated with $3 \%(\mathrm{w} / \mathrm{v})$ aqueous suspension of $\mathrm{PU}$ particles with chili pepper extract. The application of the studied samples ( $50 \mu \mathrm{L}$ once) was done on the back skin every third day and the measurements of parameters were performed 20 minutes after each application. The experiment lasted 15 days and the mice were not killed at the end.

Changes of erythema level were assessed using a Mexameter ${ }^{\circledR}$ MX 18 probe, while the hydration of stratum corneum was evaluated using a Corneometer ${ }^{\circledR} \mathrm{CM} 825$ probe by a gentle push on the skin for just a few seconds; the probes are connected to a Multiprobe Adapter System (MPA5) from Courage-Khazaka, Germany and the results appear instantly on a computer screen.

\section{Compliance with ethics requirements}

The entire experiment was first evaluated and approved by the Ethical Committee of the "Victor Babes" University of Medicine and Pharmacy Timisoara, Romania (approval no 7 from June 21st, 2016). The ethical principles for medical research and the rules of National Institute of Animal Health were respected. The animals were maintained under standard conditions (one group/one plastic cage) inside the University Biobase: 12 hours of light-dark cycle, water and food ad libitum, constant temperature (around $25^{\circ} \mathrm{C}$ ), and humidity above $55 \%$.

\section{Statistical analysis}

Data of skin-sensitivity tests were analyzed using one-way ANOVA followed by Bonferroni's posttests in order to determine the statistical difference between the studied groups; * and ** indicate $P<0.01$ and $P<0.05 . P$-values less than 0.05 were considered statistically significant.

\section{Results}

The stability of samples containing the PU microparticles with and without chili pepper extract was analyzed by studying the color, electrical conductivity, and $\mathrm{pH}$ every third day for 1 month. The maximum modifications of absorbance, used as color modification test, were $\Delta A \max$ $[350 \mathrm{~nm}]= \pm 4.87 \%$ and $\Delta \mathrm{Amax}[540 \mathrm{~nm}]= \pm 6.41 \%$, while the electrical conductivity and $\mathrm{pH}$ were maximum changed as follows: $\Delta \mathrm{k}= \pm 1.19 \%$ and $\Delta \mathrm{pH}= \pm 4.22 \%$; it can be appreciated that no important change was observed even if the samples were kept at $8^{\circ} \mathrm{C}$ (in refrigerator) or heated at $40^{\circ} \mathrm{C}$ (in a drying oven).

Figure 2 presents the samples PU_0 and PU_1, without and with chili pepper extract. The PU_0 sample contains only one particle population at $148 \mathrm{~nm}$, while PU_1 shows

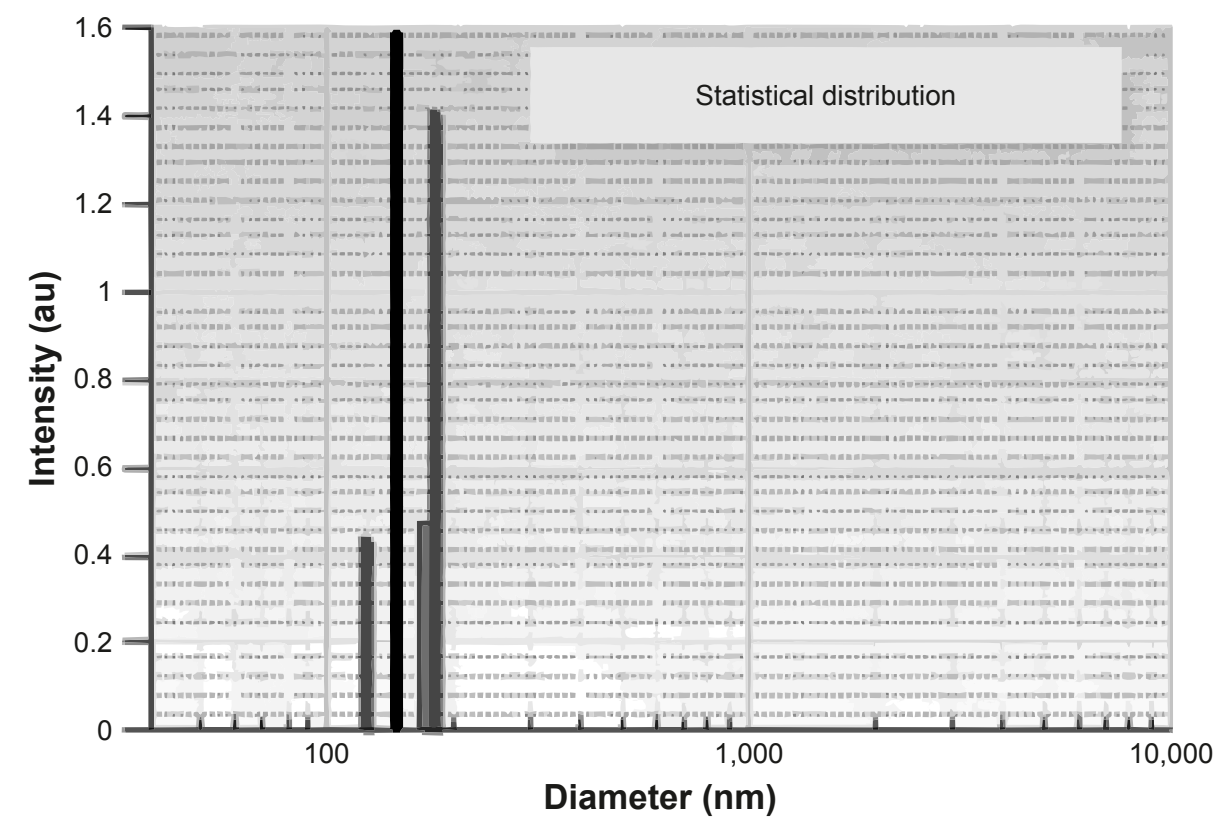

Figure 2 PU microparticles' size, PU_0 (black) and PU_I (gray). Abbreviation: $\mathrm{PU}$, polyurethane. 


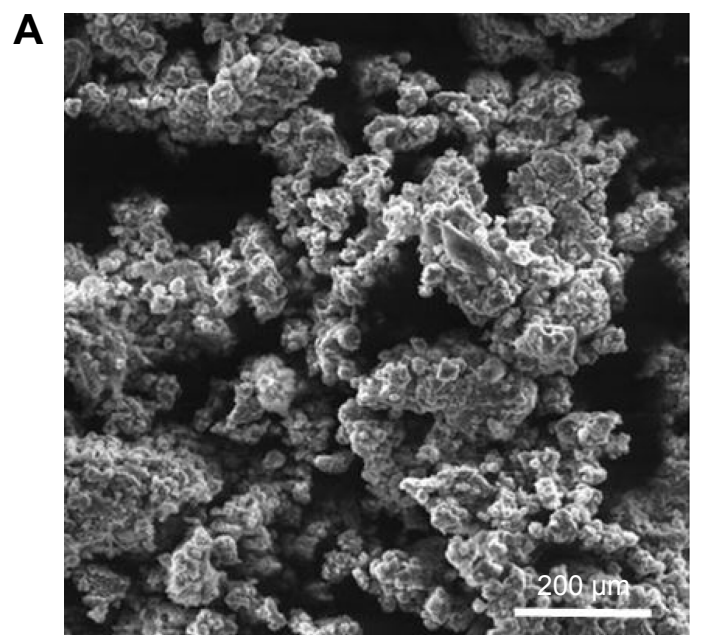

B
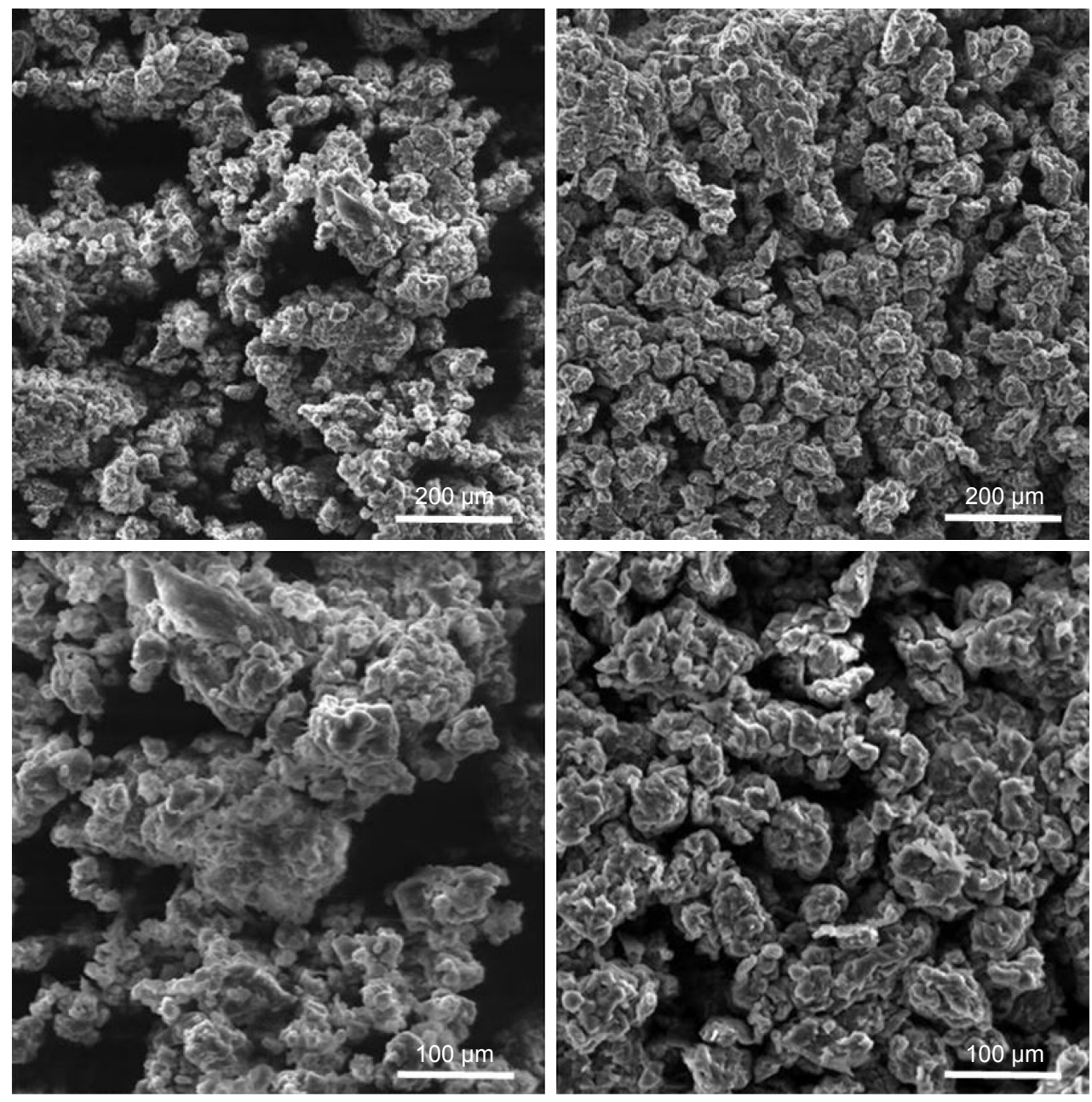

Figure 3 Scanning electron microscopy images of samples PU_0 (left) vs PU_I (right). Note: Magnification: (A) 300× and (B) 600×.

Abbreviation: PU, polyurethane.

multiple populations as follows: $19 \%$ at $123 \mathrm{~nm}, 20 \%$ at $170 \mathrm{~nm}$, and $61 \%$ at $177 \mathrm{~nm}$.

The colloidal solutions obtained from PU samples contain particles with a high tendency to form clusters; therefore, the particles' agglomeration degree was estimated by zeta-potential. Heghes et $\mathrm{a}^{28}$ indicate that the specific range of zeta-potential for unstable colloidal particles is between -30 and $+30 \mathrm{mV}$; zeta-potential is estimated by the particle mobility in an electric field by observing the Doppler shift in the scattered light. No important difference was observed between the mobility of PU particles from the two samples; zeta-potential values were $\xi_{\text {PU_ } 0}=20.1 \mathrm{mV}$ and $\xi_{\mathrm{PU} \_1}=21.6 \mathrm{mV}$. These results indicate that both samples present a medium to low stability against the tendency to form clusters. The formation of clusters was confirmed by SEM images (Figure 3), and interconnectivity between the particles was also present. The SEM images show no difference between the CAPs-loaded and CAPs-free samples; in both cases the formation of $50-100 \mu \mathrm{m}$ clusters was visible. The morphology shows no changes by the extract encapsulation.

The recorded SANS curves (Figure 4) represent the neutron intensity vs the scattering vector $(\mathrm{Q})$. The interpretation of SANS data was made with the aid of a mathematical

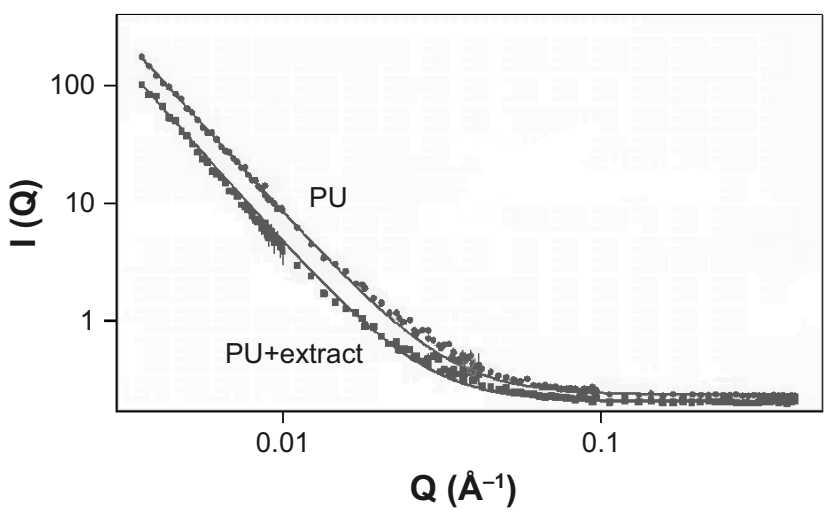

Figure 4 Small-angle neutron scattering on PU particles with and without chili pepper extract.

Abbreviation: PU, polyurethane. 
model (Eq. 2), which is the Fourier transform of the analytical function describing the real porous structure system. The parameters of the model describe the surface of the scattering objects.

Fractal objects are characterized by self-similarity within a spatial range. The fractal dimension is calculated from the p exponent of Eq. 2, and gives information about the pore surface before and after the addition of the natural extract.

For mass fractals $(2<p<3)$ fractal dimension $D$ is calculated as $D=6-p$, for surface fractals $D=p .{ }^{29}$

The fractal dimensions of empty PU and PU with CAP samples, $D$, were found as 2.97 and 3.03, indicating surfaces characterized by a transition from the mass to the surface fractal behavior, typical for clustered network of a porous systems.

The slight increase of the fractal dimension shows that there is no or only a very small change in the PU matrix pore surface by the addition of the chili pepper extract.

Very similar FTIR spectra were obtained by the analysis of the two samples (Figure 5). All important PU characteristic absorption bands were observed: $3,337 \mathrm{~cm}^{-1}$ due to the $\mathrm{N}-\mathrm{H}$ stretching vibration (urethane groups); at $1,742 \mathrm{~cm}^{-1}$ due to the $\mathrm{C}=\mathrm{O}$ bond stretching vibration (urethane groups); at $1,578 \mathrm{~cm}^{-1}$ due to the urethane $\mathrm{N}-\mathrm{H}$ bond deformation vibration; and at $1,252 \mathrm{~cm}^{-1}$ due to the $\mathrm{C}-\mathrm{N}$ bond stretching vibration coupled to the $\mathrm{C}-\mathrm{O}$ bond stretching vibration, and to the $1,116 \mathrm{~cm}^{-1}$ absorption band corresponding to the bond formed between the $-\mathrm{OH}$ and $-\mathrm{NCO}(\mathrm{C}-\mathrm{O}-\mathrm{C})$ groups of the PU. Besides these bands, absorption bands at $2,931 \mathrm{~cm}^{-1}$ and $2,857 \mathrm{~cm}^{-1}$ were observed due to asymmetric and symmetrical stretching vibrations of the $\mathrm{C}-\mathrm{H}$ bond in the methylene group. The absorption band at $1,461 \mathrm{~cm}^{-1}$ was present due

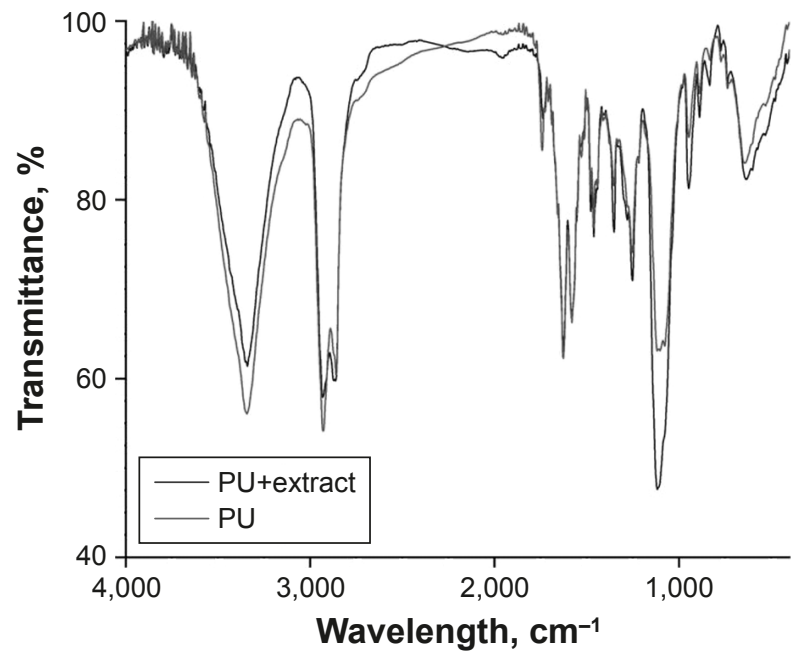

Figure 5 Overlapped Fourier transform infrared spectra. Abbreviation: PU, polyurethane. to the deformation vibration of the methylene group. The differences observed on spectra could be associated with the nanoscale phase rearrangement caused by the CAPs inclusion: an increased intensity of $\mathrm{C}=\mathrm{O}$ signal at $1,752 \mathrm{~cm}^{-1}$ for the sample with CAPs and on the other hand the intensity changes for $\mathrm{C}-\mathrm{N}$ bond at $1,353 \mathrm{~cm}^{-1}$ and for $\mathrm{C}-\mathrm{O}-\mathrm{C}$ at $1,112 \mathrm{~cm}^{-1}$. $^{30,31}$

The drug release rate is probably the most important parameter of a drug delivery system. This parameter can be estimated by the evaluation of the change in the size of the particles or by the measurement of the active component concentration inside the degradation medium; this second procedure was chosen due to the fact that it is possible for the carrier degradation rate not to be perfectly proportional to the release rate on the one hand and the chili pepper extract presents an UV-Vis maximum absorption at a higher wavelength than PU particles on the other hand (Figure 6A).

The chili pepper extract did not present a single sharp UV-Vis absorption peak; however, the $350 \mathrm{~nm}$ wavelength is referred to in the literature as a perfect wavelength to measure the concentration of its components. ${ }^{27}$ Five standard solutions of diluted extract and a calibration curve were used to evaluate the quantity of free extract in order to establish the encapsulation efficacy and the release profile. First of all, the encapsulation efficacy was determined by studying the concentration of free chili pepper extract in the acetone-water mixture used to wash the PU microparticles of sample PU_1; compared to the entire amount of extract used in the synthesis of this sample, the encapsulation efficacy was obtained as $67.9 \%$. Based on this result, the content of extract released in the degradation medium was evaluated every third day for 15 days (Figure 6B) according to the procedure described in the literature. ${ }^{26}$

No important peaks were obtained by DSC analysis in the studied temperature range (Figure 7), which is explained by the stability of PU below $300^{\circ} \mathrm{C}$; because of the low $\mathrm{Tg}$ values of $\mathrm{PU}$ materials, around $5^{\circ} \mathrm{C}$, which is explained by the decomposition of urethane and ether bonds, which results in a lower rigidity of chains. ${ }^{32}$

Skin is an organ that responds very quickly to the exposure to an external aggressive agent such as sun radiation and chemical substances. Different immune complexes are generated, circulate in the blood, and they are accumulated on the walls of the small blood vessels located in the skin and the result is a hyperergic (excess) reaction of the local nature; this process is accompanied by the redness of skin. Mexameter ${ }^{\circledR}$ MX 18 probe from Courage-Khazaka evaluates the skin pigmentation by measuring the absorption/reflection 

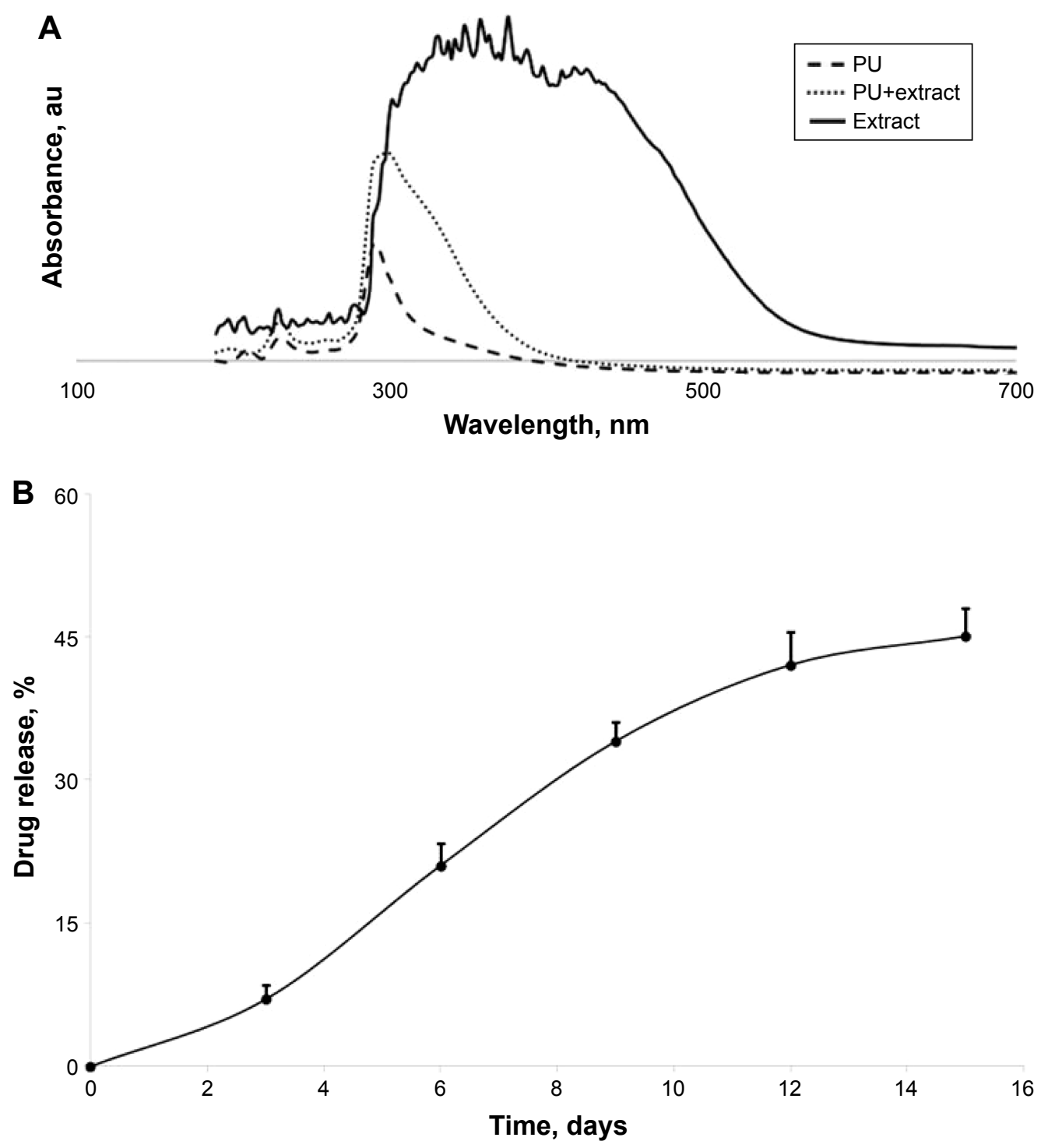

Figure 6 (A) Comparative UV-Vis spectra; (B) the release of chili pepper extract. Abbreviation: $\mathrm{PU}$, polyurethane.

of the light emitted at three different wavelengths. The measure is a very rapid one and it is non-invasive. The sensitivity of the animal skin during this research can be observed on the curve, which describes the erythema modification in the case of mice treated with pure chili pepper extract (Figure 8A, curve " 0 "). An important difference between these curves highlights the non-irritative potential of PU microparticles with and without the natural extract: the erythema change

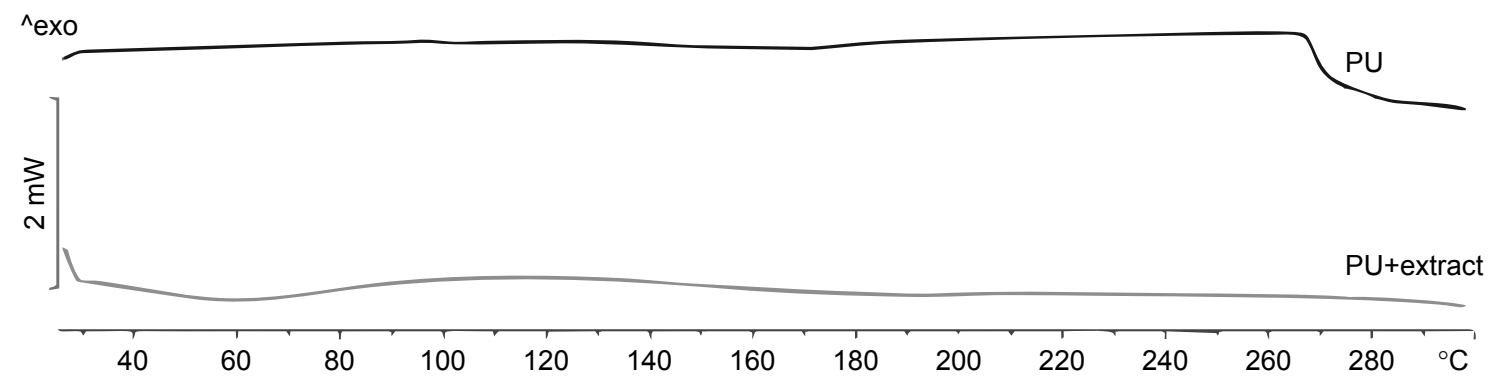

Figure 7 Differential scanning calorimetry curves.

Abbreviation: PU, polyurethane. 

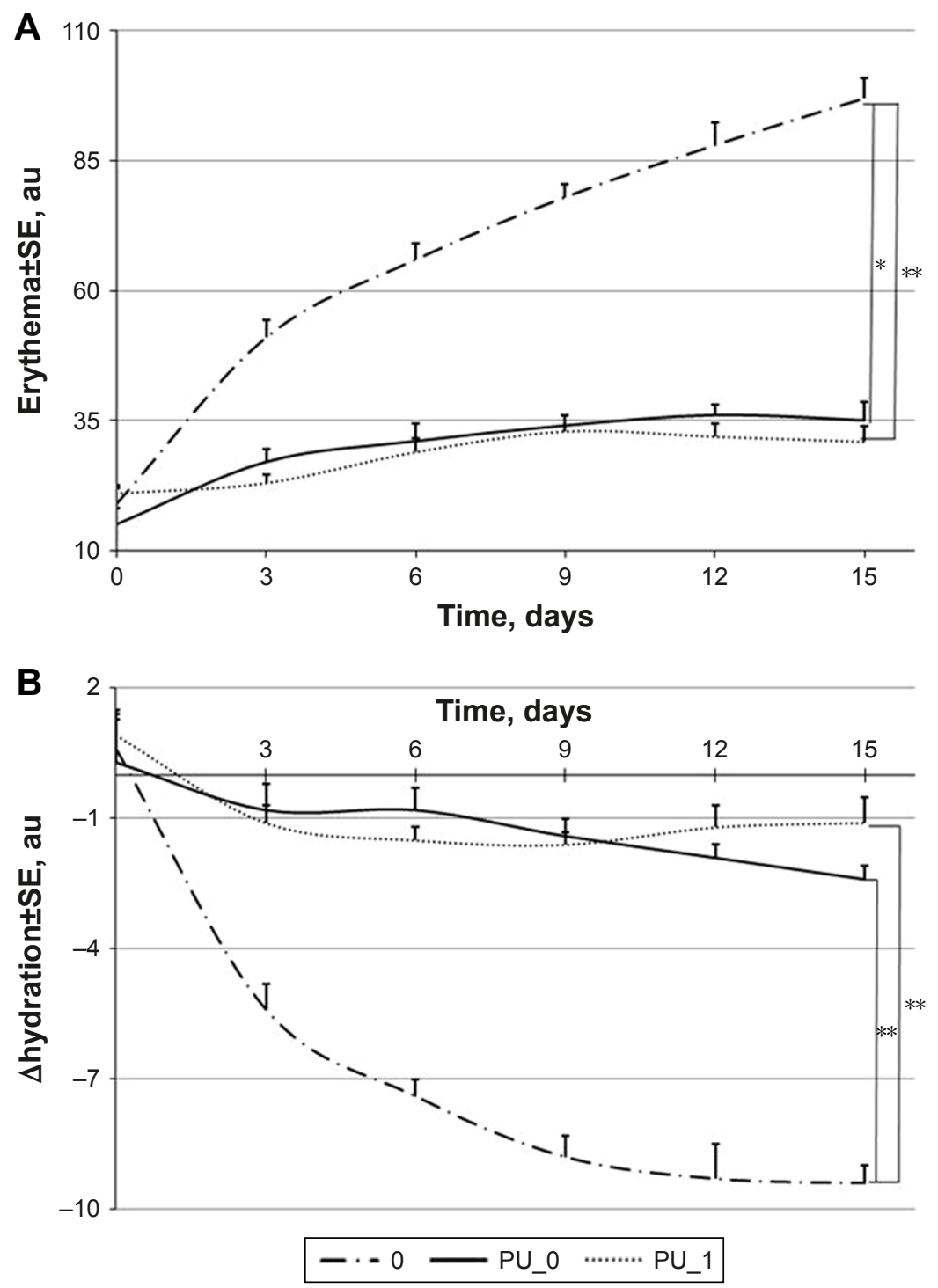

Figure 8 Evolution of skin parameters: $(\mathbf{A})$ erythema, (B) hydration state. Note: $* p<0.01$ and $* * P<0.05$.

Abbreviation: $\mathrm{PU}$, polyurethane.

is around 20 units $/ 2$ weeks in these cases compared to an increase of 70 units/2 weeks in the case of mice treated with pure extract.

The skin hydration is a dermatologic parameter whose decrease appears in all experiments when erythema and transepidermal water loss increase. It is important to observe the amplitude of the changes because every mice skin evaluation leads to a small modification of these parameters; in this experiment, mice from group " 0 " have been chosen in order to obtain the parameter change level for a known irritative agent. The skin hydration changes in the case of samples containing PU microparticles were much smaller than the reference curve "0" (Figure 8B, curves PU_0 and PU_1) and this is an important reason that determines us to assert that these particles are safe for humans.

\section{Discussion}

Many active compounds from any essential oil are unstable to heat, humidity, and exposure to oxygen; this is why the encapsulation of natural extracts represents a very good procedure to enhance their stability and other properties such as manipulation and the lipophilic-hydrophilic balance..$^{33}$ On the other hand, the encapsulation solves the problem of bad breath after eating garlic, onions, and so on. The drug carriers based on nano- and/or microparticles with slow degradation are perfect for active compounds with toxic potential as chemotherapy substances and for any drug used in chronic therapies like the treatment of osteoporosis.

The major finding of the current research was to obtain a polymeric carrier that enhances drugs' solubility, decreases 
the irritation effects, increases the tissue penetration and circulation time, and has targeting ability.

Contri et $\mathrm{al}^{34}$ studied the possibility to decrease the irritation potential caused by CAPs; they synthesized nanocapsules based on poly(ethyl acrylate, methyl-acrylate) with ammonium quaternary groups and chitosan hydrogels containing CAP-loaded nanocapsules. The in vivo and in vitro evaluations confirm that skin irritation can be reduced by encapsulation, a process that splits the loaded substance in very little reservoirs. Synthesis of capsaicin-loaded nanolipoidal carriers has been reported by Wang et al. ${ }^{35}$ They used an ultrasonicated hot oil-in-water emulsion to obtain this delivery system and verify its anti-inflammatory activity on Sprague Dawley rats and the skin irritation using the Draize procedure on Albino New Zealand rabbits. Their results suggest that carriers can significantly increase the permeation flux, the amount of cumulative permeated drug, and the retention of active substance due to the nano-size and the sustained release of organic carriers and mainly through the alternative administration routes.

\section{Pure capsaicin vs extract}

Capsaicin may induce the death of human lung and prostate cancer cells through DNA and chromosomal damage while the capsaicin epoxide is a better antiproliferative agent according to Lewinska et al. ${ }^{36,37}$ On the other hand, dihydrocapsaicin was found active against the human colon and breast cancer cells. ${ }^{38}$ Two other main compounds found in chili peppers, the reduced ascorbate and dehydroascorbate, are cofactors in hydroxylation reactions and play an important antioxidant role in the body. Other components of chili pepper extracts, such as flavonoids - a group of secondary plant metabolites, decrease the cholesterol level and present other biologic activities (they are natural antioxidants and anti-inflammatory compounds with a major impact on the immune system). ${ }^{39}$ We may speculate that the beneficial effects of chili pepper extracts present synergetic effects and the use of extracts is more appropriate than pure capsaicin in many therapies.

\section{The mediated transfer}

The encapsulation of an extract is a proper procedure used to increase its controlled and targeted delivery. A major part of nano- and microcarriers modifies the solubility of hydrophobic compounds and their surface-to-volume ratio. The polymeric delivery systems have been extensively studied due to their possibility to encapsulate a large variety of drugs; carriers based on natural polymers such as albumin, chitosan, and hyaluronic acid were developed at the same time with liposomes, dendrimers, and new hyperbranched synthetic polymers. ${ }^{40}$

Chen et $\mathrm{al}^{41}$ synthesized capsaicin-chitosan microspheres enteric-coated tablets; they studied the in vitro release and found a reduced irritation potential and a minimized change of capsaicin level in blood. The concern for the encapsulation of Chili pepper extracts has increased enormously in the last years: Dominguez-Canedo and Beristain-Guevara obtained beta-cyclodextrin microparticles, ${ }^{42}$ de Aguiar et $\mathrm{al}^{43}$ have reported the synthesis of different emulsions based on Hi-Cap 100, while maltodextrin polymers and blended biopolymers containing CAPs were also obtained. ${ }^{44,45}$ All these concerns prove once again that mediated transfer is based on carriers with good stability, high transport capacity, and increased possibility of incorporation of both hydrophobic and hydrophilic compounds; thus, the mediated transfer leads to improved clinical efficacy of plant extracts.

\section{The hemocompatibility of PUs}

The synthesis of PU drug delivery systems were reported for the first time at the beginning of this century by Bouchemal, ${ }^{46}$ but different PU applications in medicine were obtained much earlier: coatings of cardiac pacemaker and breast implants, intra-aortic and gastric balloons, inflatable implants, wound dressings, catheters, and bones reconstruction.

Numerous studies are focused on the biocompatibility and hemocompatibility of PUs, ${ }^{47-49}$ and a major part of these materials was found safe to be used in human applications. The aromatic diisocyanates, important industrial precursors, were replaced with aliphatic compounds such as HMDI, isophorone-diisocyanate, or lysine-diisocyanate in order to avoid obtaining any carcinogenic compound (amines as secondary product in isocyanates' reaction with water). Day by day, the number of studies on the toxicity of PUs increases. The cytotoxicity of our carriers was already assessed by using the Trypan Blue test on human mesenchymal stem cells; ${ }^{18}$ no toxic activity on the tested cells after 24 and 48 hours were reported by our research team.

The main aspect of chili peppers' extract remains its irritation over the digestive tract. In our current study, we found that extract encapsulation in a PU microcarrier decreases the irritation effects.

\section{Conclusion}

This paper gives the physical and chemical characterization of a PU delivery system used for the transmembrane 
transfer of a chili pepper extract. Textural and morphologic characterizations proved that PU matrix remains stable and unmodified with the addition of CAPs to the inner surface. Microparticles, with an average size between 123 and $177 \mathrm{~nm}$, with a medium to low stability against the tendency to form clusters, were synthesized during a spontaneous emulsification combined with a polyaddition reaction. The cluster formation was observed on SEM images too. No important change of the fractal dimension was revealed by SANS analysis between the hollow PU particles and particles containing chili extract. The UV-Vis analysis proved a good encapsulation efficacy (almost 70\%) and a slow release of the encapsulated extract ( $45 \%$ in 2 weeks). Bioevaluations based on the determinations of mice skin parameters such as erythema and skin hydration indicate that these particles have no irritative potential.

\section{Author contributions}

LCB and ZD participated in the extraction and encapsulation steps; AL participated in the physicochemical tests; JF interpreted the results and wrote the article; FB participated in the animal study and contributed to the final form of the manuscript; and MCT designed this study and conceived the draft. All authors contributed to data analysis, drafting and revising the article, gave final approval of the version to be published, and agree to be accountable for all aspects of the work.

\section{Disclosure}

The authors report no conflicts of interest in this work.

\section{References}

1. Masud Parvez GM. Current advances in pharmacological activity and toxic effects of various capsicum species. IJPSR. 2017;8(5):1900-1912.

2. Ryu WK, Kim HW, Kim GD, Rhee HI. Rapid determination of capsaicinoids by colorimetric method. J Food Drug Anal. 2017;25(4):798-803.

3. Simonovska J, Škerget M, Knez Željko, et al. Physicochemical characterization and bioactive compounds of stalk from hot fruits of Capsicum annuum L. Maced J Chem Chem Eng. 2016;35(352):199-208.

4. Fayos O, de Aguiar AC, Jiménez-Cantizano A, et al. Ontogenetic variation of individual and total capsaicinoids in Malagueta peppers (Capsicum frutescens) during fruit maturation. Molecules. 2017;22(5):736.

5. Zimmermann M, Schieberle P. Important odorants of sweet bell pepper powder (Capsicum annuит cv. annuиm): differences between samples of Hungarian and Moroccan origin. Eur Food Res Technol. 2000;211(3): 175-180.

6. Freire LCC, Araújo EIM, Valdevino FISP, Silva FFM, Alves LA, Bertini LM. Contribution to the phytochemical study and chemical tests of the extracts of Citrus limonium (LEMON) and Capsicum frutescens $\mathrm{L}$. (chilli pepper). HOLOS. 2015;1:21-29.

7. Lv J, Qi L, Yu C, et al. Consumption of spicy foods and total and cause specific mortality: population based cohort study. BMJ. 2015;351:h3942.

8. Daood HG, Halasz G, Palotás G, Palotás G, Bodai Z, Helyes L. HPLC determination of capsaicinoids with cross-linked $\mathrm{C} 18$ column and bufferfree eluent. J Chromatogr Sci. 2015;53(1):135-143.
9. Sahin K, Orhan C, Tuzcu M, Sahin N, Ozdemir O, Juturu V. Ingested capsaicinoids can prevent low-fat-high-carbohydrate diet and highfat diet-induced obesity by regulating the NADPH oxidase and Nrf2 pathways. J Inflamm Res. 2017;10:161-168.

10. Chapa-Oliver AM, Mejía-Teniente L. Capsaicin: from plants to a cancer-suppressing agent. Molecules. 2016;21(8):E931.

11. Juturu V. Capsaicinoids modulating cardiometabolic syndrome risk factors: current perspectives. J Nutr Metab. 2016;2016:1-11.

12. Fattori V, Hohmann MS, Rossaneis AC, Pinho-Ribeiro FA, Verri WA. Capsaicin: current understanding of its mechanisms and therapy of pain and other pre-clinical and clinical uses. Molecules. 2016;21(7):E844.

13. Deshpande J, Jeyakodi S, Juturu V. Tolerability of capsaicinoids from capsicum extract in a beadlet form: a pilot study. $J$ Toxicol. 2016:6584649.

14. Bauchy F, Mouraux A, Deumens R. Feasibility of topical applications of natural high-concentration capsaicinoid solutions in patients with peripheral neuropathic pain: a retrospective analysis. Pain Res Manag. 2016; 2016;2016:9703036.

15. Lenzi EK, Novatski A, Farago PV, Almeida MA, Zawadzki SF, Menechini Neto R. Diffusion processes and drug release: capsaicinoids loaded poly ( $\varepsilon$-caprolactone) microparticles. PLoS One. 2016;11(6): e0157662.

16. Rollyson WD, Stover CA, Brown KC, et al. Bioavailability of capsaicin and its implications for drug delivery. J Control Release. 2014;196: 96-105.

17. Lu M, Ho CT, Huang Q. Extraction, bioavailability, and bioefficacy of capsaicinoids. J Food Drug Anal. 2017;25(1):27-36.

18. Munteanu MF, Ardelean A, Borcan F, et al. Mistletoe and garlic extracts as polyurethane carriers - a possible remedy for choroidal melanoma. Curr Drug Deliv. 2017;14(8):1178-1188.

19. Sricharoen P, Techawongstein S, Chanthai S. A high correlation indicating for an evaluation of antioxidant activity and total phenolics content of various chilli varieties. J Food Sci Technol. 2015;52(12): $8077-8085$.

20. Sora GT, Haminiuk CW, da Silva MV, et al. A comparative study of the capsaicinoid and phenolic contents and in vitro antioxidant activities of the peppers of the genus Capsicum: an application of chemometrics. J Food Sci Technol. 2015;52(12):8086-8094.

21. Borcan F, Soica CM, Dehelean CA, Ganta S. Size and stability optimization for polyurethane nanostructures used as transdermal drug vehicle. Rev Chim Bucharest. 2012;63(11):1164-1166.

22. Galuscan A, Jumanca D, Borcan F, Crainiceanu Z. Comparative study on polyurethane and cyclodextrin carrier for triclosan. Rev Chim Bucharest. 2014;65(2):190-193.

23. Oprean C, Zambori C, Borcan F, et al. Anti-proliferative and antibacterial in vitro evaluation of the polyurethane nanostructures incorporating pentacyclic triterpenes. Pharm Biol. 2016;54(11):2714-2722.

24. King SM. Small-angle neutron scattering. In: Pethrick RA, Dawkins JV, editors. Modern Techniques for Polymer Characterization. Chichester, NY: John Wiley; 2003.

25. Hammouda B. A new Guinier-Porod model. J Appl Crystallogr. 2010; 43(4):716-719.

26. Albulescu RC, Borcan F, Paul C, Velea I, Puiu M. Development and in vitro evaluation of polyurethane microparticles as carrier for bevacizumab: an alternative treatment for retinopathy of prematurity. Int Curr Pharm J. 2014;3(6):275-279.

27. Nagy Z, Daood H, Ambrozy Z. Determination of polyphenols, capsaicinoids, and vitamin $\mathrm{C}$ in new hybrids of chili peppers. $J$ Anal Met Chem. 2015.

28. Heghes A, Soica CM, Ardelean S, et al. Influence of emulsifiers on the characteristics of polyurethane structures used as drug carrier. Chem Cent J. 2013;7(1):66.

29. Schmidt PW. Small-angle scattering studies of disordered, porous and fractal systems. J Appl Crystallogr. 1991;24(5):414-435.

30. Mishra AK, Chattopadhyay DK, Sreedhar B, Raju KVSN. FT-IR and XPS studies of polyurethane-urea-imide coatings. Prog Org Coat. 2006; 55(3):231-243. 
31. Gurunathan T, Mohanty S, Nayak SK. Isocyanate terminated castor oil-based polyurethane prepolymer: synthesis and characterization. Prog Org Coat. 2015;80:39-48.

32. Pilch-Pitera B. Examination of the enzyme resistance of polyurethane powder coatings. J Poly Environ. 2013;21(1):215-223.

33. Dolca C, Ferrandiz M, Capablanca L. Microencapsulation of rosemary essential oil by co-extrusion/gelling using alginate as a wall material. J Encaps Adsorpt Sci. 2015;5:121-130.

34. Contri RV, Frank LA, Kaiser M, Pohlmann AR, Guterres SS. The use of nanoencapsulation to decrease human skin irritation caused by capsaicinoids. Int J Nanomedicine. 2014;9:951-962.

35. Wang XR, Gao SQ, Niu XQ, et al. Capsaicin-loaded nanolipoidal carriers for topical application: design, characterization, and in vitro/ in vivo evaluation. Int J Nanomedicine. 2017;12:3881-3898.

36. Lewinska A, Jarosz P, Czech J, et al. Capsaicin-induced genotoxic stress does not promote apoptosis in A549 human lung and DU145 prostate cancer cells. Mutat Res Genet Toxicol Environ Mutagen. 2015; 779:23-34.

37. Lewinska A, Chochrek P, Smolag K, Rawska E, Wnuk M. Oxidantbased anticancer activity of a novel synthetic analogue of capsaicin, capsaicin epoxide. Redox Rep. 2015;20(3):116-125.

38. Oh SH, Kim YS, Lim SC, Hou YF, Chang IY, You HJ. Dihydrocapsaicin (DHC), a saturated structural analog of capsaicin, induces autophagy in human cancer cells in a catalase-regulated manner. Autophagy. 2008;4(8):1009-1019.

39. Kelepouri D, Mavropoulos A, Bogdanos DP, Sakkas LI. The role of flavonoids in inhibiting Th17 responses in inflammatory arthritis. J Immunol Res. 2018;2018:1-11.

40. Chakravarthi SS, Robinson DH, De S. Nanoparticles prepared using natural and synthetic polymers. In: Thassu D, Deleers M, Pathak YV, editors. Nanoparticulate Drug Delivery Systems. Boca Raton, FL: CRC Press; 2007;3:51.

41. Chen J, Huang GD, Tan SR, Guo J, Su ZQ. The preparation of capsaicinchitosan microspheres (CCMS) enteric coated tablets. Int J Mol Sci. 2013;14(12):24305-24319.
42. Domínguez-Canedo IL, Beristain-Guevara CI. Microencapsulation of Habanero chilli (Capsicum chinense) oleoresin in beta-ciclodextrin and antioxidant activity during storage. In: Memorias del Congreso Internacional "III European Drying Conference - EuroDrying 2011", Palma de Mallorca, Espana.

43. de Aguiar AC, Silva LPS, de Rezende CA, Barbero GF, Martínez J. Encapsulation of pepper oleoresin by supercritical fluid extraction of emulsions. J Supercrit Fluids. 2016;112:37-43.

44. Juárez-Goiz JM, Gómez-Leyva JF, Bernardino-Nicanor A, GonzálezCruz L, Andrade-González I. Capsaicinoid microencapsulation of chili pepper fruit (C. annuum) oleoresin by complex coacervation. J Food Meas Charact. 2018;12(1):278-284.

45. Seliem EI, Mahmoud KF, Amin AA, Salama MF. Extraction of oleoresin by supercritical fluid extraction, capsulation and its physiochemical properties. Int J Curr Res Acad Rev. 2018;3(5):1-11.

46. Bouchemal K, Briançon S, Perrier E, Fessi H, Bonnet I, Zydowicz N. Synthesis and characterization of polyurethane and poly(ether urethane) nanocapsules using a new technique of interfacial polycondensation combined to spontaneous emulsification. Int J Pharm. 2004;269(1): 89-100.

47. Yang J, Chen H, Yuan Y, Sarkar D, Zheng J. Synthesis and characterization of biocompatible polyurethanes for controlled release of hydrophobic and hydrophilic drugs. Front Chem Sci Eng. 2014;8(4): 498-510.

48. Marois Y, Guidoin R. Biocompatibility of polyurethanes. In: Madame Curie Bioscience Database [Internet]. Available from: www.ncbi.nlm. nih.gov/books/NBK6422. Accessed September 4, 2018.

49. Tavakol S, Kiani V, Tavakol B. Toxicity Concerns of Nanocarriers. Nanotechnology-Based Approaches for Targeting and Delivery of Drugs and Genes. London, UK: Elsevier; 2017:453-484.
International Journal of Nanomedicine

\section{Publish your work in this journal}

The International Journal of Nanomedicine is an international, peerreviewed journal focusing on the application of nanotechnology in diagnostics, therapeutics, and drug delivery systems throughout the biomedical field. This journal is indexed on PubMed Central, MedLine, CAS, SciSearch $®$, Current Contents ${ }^{\circledR} /$ Clinical Medicine,

\section{Dovepress}

Journal Citation Reports/Science Edition, EMBase, Scopus and the Elsevier Bibliographic databases. The manuscript management system is completely online and includes a very quick and fair peer-review system, which is all easy to use. Visit http://www.dovepress.com/ testimonials.php to read real quotes from published authors. 